\title{
"NOVA ET VETERA" \\ COMO REVERENCIA \\ IRREVERENTE: \\ RESPUESTA A \\ GREGORY ROPER \\ Carlos Gutiérrez Lozano*
}

\begin{abstract}
Aunque el artículo del doctor Roper tiene como núcleo un, a mi parecer, logrado análisis del "Cuento del capellán de monjas", uno de los Cuentos de Canterbury de Geoffrey Chaucer, al principio establece una serie de afirmaciones y tesis sobre la tradición occidental de la cuales Chaucer es una eminente encarnación. A estas afirmaciones iniciales se enfocarán mis observaciones y comentarios.

La tesis central es que en Occidente, la relación con la tradición es dinámica, a la vez seria y lúdica, que el doctor Roper llama, a mi juicio atinadamente, "reverencia irreverente" o "irreverencia reverente", pero que también podría ser un continuo proceso hegeliano de Aufhebung, es decir, de superación que no anula sino conserva lo anterior; o también, como voy a proponer, una relación de nova et vetera.

El otro tipo de relación con la tradición es la relación estática, reverente. El doctor Roper pone como ejemplo dos grandes tradiciones "orientales": el confucianismo y el islam. Hasta donde alcanzan mis conocimientos, concuerdo con sus afirmaciones, pues en ellas no hay nova et vetera, sino solo vetera, lo viejo, de modo que surge un fenómeno peculiar que Heidegger menciona respecto de la historia de la metafísica, pero que bien podemos utilizar aquí:
\end{abstract}

La tradición que de este modo llega a dominar no vuelve propiamente accesible lo "transmitido" por ella, sino que por el contrario, inmediata y

* Departamento Académico de Estudios Generales, ITAM. 
regularmente lo encubre. Convierte el legado de la tradición en cosa obvia y obstruye el acceso a las "fuentes" originarias de donde fueron tomados, en forma parcialmente auténtica, las categorías y los conceptos que nos han sido transmitidos. ${ }^{1}$

Lo que Heidegger quiere mostrar, y me parece que el doctor Roper también, es que la actitud reverente hacia la tradición la vuelve ininteligible, que se hagan cosas sin saber bien a bien qué significan, y que cuando se ponen en cuestión, se responda instintivamente: ¡siempre ha sido así! En cambio, Heidegger también considera que hay otro tipo de relación con la tradición, a saber: "El descubrimiento de la tradición y la averiguación de lo que ella 'transmite' y del modo como lo transmite, puede ser asumido como tarea autónoma". ${ }^{2}$ Este descubrimiento y averiguación heideggerianos pueden asimilarse a la actitud de irreverente irreverencia o de reverente irreverencia que señala el doctor Roper. Claro está que Heidegger achaca a la tradición occidental precisamente esa actitud pasiva, lo cual contradiría la tesis del doctor Roper, pero él mismo afirma que en Occidente a veces estamos de un lado (pura reverencia), a veces del otro lado (pura irreverencia) y otras veces en el medio (reverencia irreverente).

Respecto del islam, el doctor Roper dice que la división entre sunitas y chiitas está motivada más por cuestiones políticas (la sucesión de Mahoma) que por cuestiones hermenéuticas (el sentido del texto). Me parece que tanto en el islam como en Occidente tenemos una mezcla de ambas motivaciones, puesto que en el islam las escuelas de derecho (sharia) debaten continuamente sobre el sentido del texto del Corán para determinar su aplicación en casos concretos. Por su parte, en Occidente tenemos que el cisma entre la Iglesia latina y la Iglesia ortodoxa no fue solo la famosísima cuestión del filioque, sino también la cuestión político-religiosa de la autoridad que vela sobre la tradición: el papa como cabeza única de toda la iglesia o la autonomía autocefálica de cada patriarcado. O más refinadamente durante el cisma de Occidente con Lutero: al lado de las cuestiones estrictamente hermenéuticas

${ }^{1}$ Martin Heidegger, Ser y tiempo, § 6, [1927] 2003, Madrid, Trotta, tr. de Jorge Eduardo Rivera, p. 45.

${ }^{2}$ Ibid., p. 44. 
(¿de verdad hay en la Sagrada Escritura una fundamentación de los siete sacramentos?, ¿en efecto instituyó Jesús la eucaristía como transformación milagrosa del pan y el vino en su cuerpo y sangre, es decir, la Biblia afirma la transubstanciación?), hay una cuestión eminentemente política: la relación entre individuo y comunidad, entre individuo e Iglesia o bien la relación entre individuo y autoridad. Lutero afirmó que la primacía está en el individuo (cada uno es y debe ser intérprete de la Escritura), con lo que desfondó la importancia de la iglesia y del Papa como garantes de la tradición. Así pues, en las cuestiones de la tradición, parece ser una constante la intervención conjunta de factores hermenéuticos y sociopolíticos.

En seguida, el doctor Roper afirma que en Occidente pudimos haber seguido el camino de esa tradición estática, pues "la Torá o Tanaj pudo haber tomado el mismo estatus del Corán". Bien, hay que decir que la Torá no es el libro sagrado de Occidente, sino la Biblia, es decir, la Torá y el Nuevo Testamento. De hecho, la Biblia en su conjunto es un ejemplo maravilloso de reverencia irreverente hacia la tradición (pensemos, por ejemplo, en los Libros de los reyes por un lado y el libro de las Crónicas por otro, en los que muchas veces se narran los mismos acontecimientos, pero con una perspectiva diferente). De hecho, el doctor Roper señala que hay dos figuras fundamentales para la autocomprensión de Occidente de su comportamiento frente a la tradición, y una de ellas es precisamente una figura bíblica del Nuevo Testamento: Jesús de Nazaret. Me parece meridianamente clara la reverencia de Jesús hacia la tradición, pues dice de sí mismo que "no he venido a abolir la ley sino a darle plenitud" (Mt 5,17), y al mismo tiempo su irreverencia la representan los maestros de la ley, los fariseos: "han oído ustedes que se dijo [...] pero yo les digo" (Mt 5, 21-22). Si algo llamó la atención de aquellos que escuchaban a Jesús era su manera inaudita de interpretar los textos sagrados y darles una significación cada vez más amplia y cada vez más liberadora.

Ahora bien, el doctor Roper plantea una cuestión clave a mi parecer:

Nótese aquí la delicada dificultad, que espero explorar después, quizá en la discusión: ¿dónde el respeto, la reverencia, se vuelca en simple obediencia y dónde la investigación crítica se vuelca en lo meramente irreverente 
e irrespetuoso que no se somete a nada, sino que disuelve todo el pasado en el ácido de la arrogancia centrada en el presente? Esta, sugiero, es la fina línea que la cultura occidental siempre está cruzando, a veces hacia un lado y a veces hacia el otro, siempre necesitada de corrección. Pero su postura autocrítica está siempre allí para proporcionar la corrección.

Pues bien, como mi aporte a la discusión sobre esta cuestión decisiva quiero proponer unas palabras del mismo Jesús, que después buscaré ilustrar con varios ejemplos. Al final de una larga serie de parábolas, Jesús concluye de la siguiente manera: “Así, todo escriba que se ha hecho discípulo del Reino de los Cielos es semejante al dueño de una casa que saca de sus arcas lo nuevo y lo viejo" (Mt. 13, 52). El equilibrio siempre fluctuante entre reverencia e irreverencia puede ser iluminado a través de la relación entre lo nuevo y lo viejo. Cuando lo nuevo prevalece sobre lo viejo, se da la mera irreverencia y la disolución; cuando solo se mantiene lo viejo sin la presencia de lo nuevo, hay tradicionalismo absurdo y carente de posibilidades.

El doctor Roper nombra como figuras de la actitud reverente-irreverente hacia la tradición a Sócrates y a Jesús de Nazaret. En Sócrates tenemos una clara reverencia irreverente porque se da la mezcla de lo viejo (la veneración a los dioses, la búsqueda de la verdad) con lo nuevo (la conciencia personal y la mayéutica como método para el encuentro de la verdad). En Jesús tenemos una clara reverencia irreverente porque se da lo viejo (las promesas mesiánicas, la ley) junto con lo nuevo (el cumplimiento de las promesas, la plenitud de la ley). Y aquí quiero dar un primer ejemplo de nova et vetera, no sin pedir una segunda disculpa al doctor Roper, pues en su proyecto original él había considerado tratar sobre Chaucer y San Felipe Neri y en su documento final no habló sobre el santo florentino del siglo XVI. Pero me parece, sobre todo a partir de lo dicho sobre Sócrates y Jesús, que la figura de Felipe Neri era muy apropiada, y me permitiré apuntar algunas cosas al respecto.

Y es que precisamente san Felipe Neri ha sido llamado en varias ocasiones el "Sócrates cristiano" o como lo hace Walter Nigg, "Sócrates 
en sotana". Esto mismo ya es una mezcla de reverencia irreverente o de nova et vetera. Nigg dice a propósito de bautizar a Sócrates, lo que a primera vista se presenta como algo absurdo o inútil o contradictorio, que

la posibilidad socrática es intemporal. Kierkegaard ha señalado expresamente la necesidad de una nueva aparición de Sócrates e incluso la ha encarnado en su persona en una medida considerable. El danés considera el surgimiento de una moderna figura de Sócrates como una meta que debe desearse en lo más íntimo. Esta esperanza no permaneció en el terreno de los deseos piadosos, sino que ha tomado figura muchas veces en la historia, la más impresionante de todas en la personalidad de Felipe Neri. ${ }^{3}$

En efecto, igual que Sócrates, Felipe Neri se dedicó a despertar las conciencia de los hombres y mujeres de su tiempo, especialmente de los jóvenes, y procedía de una manera semejante al mosquito de Atenas: iba por las plazas, tomaba a los jóvenes y por medio de preguntas, bromas y pequeños sermones, los motivaba a hacer algo por los demás. Meriol Trevor define a san Felipe con unas palabras que igualmente podrían ser aplicadas a Sócrates, excepto por supuesto lo referente a la ordenación sacerdotal:

Lo que hizo lo realizó sin ningún instrumento de poder. Nunca ocupó un cargo importante. Ni siquiera fue sacerdote sino hasta después de los treinta cinco años. No escribió ningún libro. No fue en absoluto un predicador popular o un líder religioso; en realidad, predicó muy poco. $\mathrm{Su}$ obra se realizó solo mediante la influencia personal. ${ }^{4}$

Hay una clara diferencia: Felipe utilizó el camino de la alegría, de la risa, de la diversión como nova respecto a lo anterior, pues sabía que la alegría es mejor que la amenaza o la tristeza (o la ironía socrá-

${ }^{3}$ Walter Nigg, Felipe Neri, el bufón de Dios, s/f, México, tr. de Carlos Gutiérrez, p. 37.

${ }^{4}$ Meriol Trevor, San Felipe Neri, apóstol de Roma, 1986, Santander, Sal Terrae, tr. Aureli Boix, p. 11. 
tica) para llevar a las personas hacia el bien. Ahondado en las diferencias, nuevamente Nigg afirma:

El Sócrates cristiano es sobre todo menos racional que el modelo griego; no despreciaba de ningún modo el pensamiento racional, pero le obsequió mucho menos confianza. La convicción cristiana le concedió al socrático Felipe el derecho de representar con mayor fuerza su exhortación a pensar en el alma. El apóstol de Roma encarnó la misión del mosquito en forma cristiana y no en forma griega. La diferencia condicionada por esta situación se muestra especialmente en la muerte tan diferente de ambos hombres. ${ }^{5}$

En efecto, Sócrates muere condenado por los ciudadanos de su amada Atenas, mientras que Felipe muere apaciblemente a los ochenta años aclamado ya en vida por la ciudad eterna.

Por otro lado, y esta es una segunda ilustración, Felipe Neri representa con toda claridad el equilibro entre el nova et vetera de la tradición cristiana al ser una mezcla original de venerables tradiciones de la Iglesia: la Iglesia primitiva (en especial Juan Casiano, 360-435), san Benito de Nursia (480-547), santo Domingo de Guzmán (1170-1221) y san

134 Ignacio de Loyola (1491-1556). Así lo expresa el cardenal John Henry Newman: "el alumno florentino de santo Domingo cayó bajo la inspiración de san Benito en el territorio de Nápoles, y encontró a san Ignacio en persona, de cuerpo entero, cuando llegó a Roma". ${ }^{6}$ El mismo Newman escribe a manera de resumen lo que tomó de cada una de estas tradiciones espirituales dentro de la gran tradición católica: "Luego, desde que aprendió de Benito qué ser y de Domingo qué hacer, permitidme considerar que de Ignacio aprendió cómo hacerlo". ${ }^{7}$ La tercera ilustración de nova et vetera respecto a Felipe Neri es la mezcla entre lo viejo (el inalterable pero dinámico dogma de la Iglesia) y lo nuevo (algunas características de la Florencia de su tiempo, como el espíritu demo-

${ }^{5}$ Nigg. op. cit., pp. 39-40.

${ }^{6}$ John Henry Newman, "La misión de San Felipe", Newmaniana 15 (1995), tr. de Fernando M. Cavaller, p. 22.

${ }^{7}$ Ibid., p. 26. 
crático, el amor al arte, y la música). Felipe representa lo viejo (la pretensión cristiana de la salvación) junto con lo nuevo (esa salvación en medio del mundo y no al margen, como antaño). De este modo, tenemos que

Felipe fue un representante de la antigua tradición fraternal en un periodo paternalista, cuando el modelo de relación que surgía con fuerza era el de gobernante-súbdito. Los frailes habían reanimado el ideal de la fraternidad en el siglo XIII, saliendo al mundo como monjes en acción de servicio. Felipe llevó esta apertura al mundo un paso más adelante al no permitir votos en su comunidad. ${ }^{8}$

Otra ilustración en el ámbito religioso católico: después de casi cuatrocientos años, el Concilio Vaticano II vino a sacudir la comprensión de la Iglesia católica y de su misión en el mundo. El Concilio Vaticano I, en general, me parece un ejemplo de reverencia estática, mientras que la meta del Concilio, en palabras del hoy san Juan XXIII, era el aggiornamento (la puesta al día) de la Iglesia. Pues bien, no deja de llamar la atención que los "motores" del Concilio hayan sido grandes teólogos que se caracterizaron por tener una misma actitud: regresar al pasado de la Iglesia para poder ver hacia el futuro. En efecto, Karl Rahner, Jean Daniélou, Henry de Lubac, Yves Congar, Marie Dominique Chenu, el mismísimo Joseph Ratzinger, etc., fueron grandes teólogos "progresistas" porque eran excelentes patrólogos, es decir, grandes conocedores de las doctrinas de los primeros padres de la Iglesia. Allí encontraron posibilidades inexploradas, o apagadas o tergiversadas, y entonces, con una actitud de profunda reverencia y al mismo tiempo de inaudita novedad respecto a la tradición, pudieron hacer una nueva mezcla de nova et vetera. Por eso no llama la atención que el doctor Roper llegue a conclusiones semejantes al final de su análisis del "Cuento del capellán de monjas", cuando afirma que "es en esta irreverencia que nosotros no solamente, como lo hizo Chaucer, nos abrimos a nuevas formas de conocimiento y expresión, sino que encontramos las profundas verdades de las formas tradicionales de expresión que estuvieron allí todo el tiempo".

${ }^{8}$ Trevor, op. cit., p. 9. 
Veamos ahora ejemplos más en relación directa con Occidente. Es ya lugar común decir que la cultura occidental bebe de dos fuentes fundamentales: el pensamiento griego y la revelación judeocristiana, o bien, que Occidente ha mirado siempre hacia Atenas y hacia Jerusalén. ${ }^{9}$ En palabras del gran historiador Christopher Dawson:

Durante todo el periodo que abarcan los siglos del cuarto al décimo séptimo estuvo consistentemente dominado por las dos grandes tradiciones del cristianismo y de la cultura clásica, y aunque hubo grandes cambios de tono, método y contenido, los dos elementos básicos permanecieron constantes. ${ }^{10}$

Por lo anterior, la Ilustración en general o el movimiento del enciclopedismo francés en particular pueden ser considerados tiempos de irreverencia hacia la tradición, "que casi destruyó el triple orden tradicional de la Cristiandad: Iglesia, Estado y Estudio", "11 pues no hay más nova et vetera, sino solo nova: ya no eran la cultura clásica y el cristianismo las tradiciones dominantes, que habían sido marginadas como superstición o saberes inútiles. Se barrió con el pasado y solo existía lo nuevo. En palabras de Dawson, "antes de comenzar la revolución industrial, la nueva filosofía ya estaba preparando el camino para su triunfo. La ciencia y la industria eran las dos alas del ejército del progreso que se iban a coordinar y unificar mediante un sistema reformado de educación racional". ${ }^{12}$

Y concluyo con algunas ilustraciones actuales. Lo que digo acerca de nova et vetera es muy básico, quizá obvio, pero me parece fundamental el hecho de buscar conciliar o mantener en equilibrio lo antiguo y lo nuevo, ya que uno de los peligros actuales, que se repite demasiado, es considerar solo lo nuevo y abandonar sin más lo pasado: Nadie

${ }^{9}$ Dawson considera que hay otra tercera que no puede ser menospreciada, a saber, "la tradición autóctona de los propios pueblos occidentales". Christopher Dawson, La crisis de la educación occidental, 1962, Madrid, Rialp, tr. de Esteban Pujals, p. 123.

${ }^{10}$ Ibid., p. 47.

${ }^{11}$ Ibid., p. 51.

${ }^{12}$ Ibid., p. 58. 
en su sano juicio podría poner en duda las ventajas de la comunicación digital, pero muchos han señalado el peligro de tomarla en términos absolutos: está bien el Facebook, pero no hay que olvidar la relación face to face o el book. Está bien el texting, pero no hay que olvidar el escribir con la mano sobre el papel. Están bien los juegos de video educativos para nuestros hijos pequeños, pero no hay que olvidar los juegos al aire libre...

De manera académica, lo afirma con contundencia el historiador Marc Bloch: "la incomprensión del presente nace fatalmente de la ignorancia del pasado". ${ }^{13}$ Por ello, las humanidades son tan importantes en nuestro tiempo, aunque en muchos lados no se las valore o incluso hayan sido marginadas desde hace tiempo, cuando "este ideal aristocrático y humanista fue sustituido gradualmente por el utilitarismo democrático de la educación estatal obligatoria por un lado y, por el otro, por el ideal de la especialización científica". ${ }^{14}$ Estoy convencido de que las humanidades son esenciales, pues se encargan, entre otras cosas, de posibilitar la frase de Jesús: sacar del tesoro de nuestra tradición cosas nuevas y cosas antiguas; se encargan, en palabras del doctor Roper siguiendo a Chaucer, de que a nuestra cultura actual no le falte el viejo gallo "que tiene la gran meta de instruirnos" ni el nuevo zorro que "sacuda al gallo para hacerlo pensar más ágilmente".

Ese es, a mi parecer, uno de los aspectos más fuertes de nuestro Departamento Académico de Estudios Generales, pues al lado de las más modernas teorías matemáticas o prácticas contables, al lado de la cibernética o las fianzas y los seguros, que sin duda sacuden al gallo para que piense con rapidez, el alumno se confronta con Sófocles y Dante, con Descartes y Hobbes, con Marx y Nietzsche, que son los viejos gallos encargados de instruirnos. Sólo así la tradición se mantiene como lo que debe ser: una fuente inagotable de posibilidades de realización humana.

${ }^{13}$ Marc Bloch, Introducción a la historia, 1987, México, FCE, tr. de Pablo González Casanova y Max Aub, p. 38.

${ }^{14}$ Dawson, op. cit., p. 121. 
CITAM Derechos Reservados.

La reproducción total o parcial de este artículo se podrá hacer si el ITAM otorga la autorización previamente por escrito. 